Article

\title{
Adolescent ELLs Improve Their Academic English while Learning about the UN Online
}

\author{
Miriam Eisenstein Ebsworth ${ }^{1, *}$, Chencen Cai ${ }^{1}$ and Lauren McCoy ${ }^{2}$ \\ 1 Department of Teaching and Learning, New York University Steinhardt, New York, NY 10003, USA; \\ cc3595@nyu.edu \\ 2 Department of Curriculum and Teaching, Columbia University Teachers College, New York, NY 10027, USA; \\ lm3278@tc.columbia.edu \\ * Correspondence: Miriam.Ebsworth@nyu.edu; Tel.: +1-212-998-5195
}

Received: 16 December 2018; Accepted: 8 February 2019; Published: 13 February 2019

check for updates

\begin{abstract}
This action research project aimed at evaluating and revising Actionthroughwords (ATW), an online course on language learning through content for high school English language learners. Our multifaceted purpose is to help English language learners in an English language arts class to enhance their academic English language and literacy, while learning online about the work of the UN for health and peace worldwide. A teacher and nineteen students in a public high school bilingual program acted as learner-consultants, with a shift of learners' roles to one of authority and engagement. Using a mixed design, data came from questionnaires, classroom observation, and interviews with the teacher and eight of her students. All participants responded affirmatively to the ATW site and expressed appreciation not only for the content but also for focused activities to enhance vocabulary development and grammatical awareness. Results showed students' view of the UN was somewhat positive to begin with and became more positive over time. Participants recommended revision of ATW to make content more accessible through scaffolding and first language support and to offer additional games and videos appropriate for teenagers' interests and modes of learning. Differentiated instructional materials and strategies integrated with the school curriculum were also suggested for future implementation of the course.
\end{abstract}

Keywords: CALL (Computer-assisted language learning); language through content; adolescent language learners; ELLs (English language learners), academic literacy; online learning; United Nations; action research; ESL (English as a second language); peace education

\section{Introduction}

While a language-through-content methodology has been accepted in the field of second language learning, and engaging the affordances of the Internet to promote such learning has been widely suggested (Gimeno 2008), studies that document the use of online thematic courses to promote English learning are limited. The online course Actionthroughwords: Learning English While Learning about the United Nations (ATW) attempts to support English development for learners and also to provide information on the work of the UN to promote peace, development, and international understanding.

The action research study presented here contributes to the conversation on how diverse learners can use web-based materials to promote English acquisition and a global orientation towards working for a more peaceful world. This phase of the research partnered with a high school for English learners (ELLs) in an urban Northeastern US setting. A teacher volunteer and 19 of her students, ELLs with high beginner to intermediate English proficiency, used seven of the course units as an enrichment of their English language arts class, described below. We hoped to inspire these students to join the work for peace, and as an outcome of their experience with the online course, to develop community-based 
projects that would be mutually beneficial. Service learning projects such as these can promote a sense of community engagement as well as cognitive and linguistic development (Rodriguez-Arroyo and Vaughns 2015). Data from this project will also be an important step in a formative evaluation and revision of the online course with the goal of making it more attractive to diverse teens who are in the process of acquiring English.

\section{Background}

Since the publication of Mohan's seminal text (Mohan 1986), the effectiveness of a content-based approach to language learning has become widely accepted. Referred to as CLIL (content and language integrated learning) in the European context (Commission of the European Communities 2003), this pedagogical alternative enhances language acquisition while providing the benefit of developing the learner's knowledge (Coyle et al. 2010). It is embedded in several teaching models which, despite their differences, share commonalities we have tried to reflect in developing the ATW online course.

ATW includes authentic materials, connects learners to the real world digitally, and allows for "focus on form" through developing awareness of language (Doughty and Williams 1998). It provides richly contextualized examples via texts of speeches, readings, poetry, music, and lyrics. In addition, an advantage of Internet-based learning involves empowering individuals to make their own choices of the order in which they investigate aspects of content and the depth of their engagement (Allwright and Hanks 2009). In the current study, Erin (pseudonym), a volunteer teacher, used the ATW site as an addition to an English Language Arts class for ELLs; their experiences and outcomes are documented below. Themes woven throughout the course being investigated include: empathy, cooperation and communication, multicultural understanding, human rights, and conflict resolution. The site also promotes an acceptance of linguistic differences, including respect for alternative varieties of language (Canagarajah 2013).

Technological development continues to challenge second language (L2) teachers and materials developers to integrate innovations into their curricula (Hubbard 2008). Effective use of technology promotes critical thinking (Daud and Husin 2004), can have a positive transformative effect on students' culture of learning (Hamdan 2014), and facilitates social integration, communication, and cooperation in language classrooms (Osborn 2006). Instructional technology also encourages student-oriented approaches in L2 pedagogy and supports students' developing expertise in computer use (Warschauer et al. 2004).

An additional aspect of this project is to take a critical pedagogical stance and empower students by giving them the role of consultants. It was our goal to create a community of learning that would include the teacher, the student consultants, and the researchers.

We propose to revise the ATW site, originally developed for adults, for high-school-aged English language learners (ELLs), to support their sociolinguistic growth, and once again to encourage them to design peace-oriented projects that will benefit their own communities. The content, which includes exploration of UN programs and initiatives around the world, is relevant to the immigrant experiences of the learners while expanding their awareness of geography, culture, and history. Thus, the teaching and learning involved in our research reflected a funds-of-knowledge approach (González et al. 2009).

Our project was developed in collaboration with administrators and teachers at MMHS, the Multilingual Multicultural High School (pseudonym). The teacher and learners volunteered for the project. The learners took the role of users/consultants. Erin decided on how to incorporate ATW into her class, taking a formative perspective on what would be most successful. Students and teacher provided feedback to the researchers and each other on what was useful and what changes to the online course might be helpful. While our data here are limited to the use of ATW within a particular class setting, we hope the insights gained will have relevance for other contexts. 


\subsection{A Language-through-Content Approach}

A theme-based approach to language teaching and learning reflects current best practices in second language (L2) pedagogy. Indeed, state-of-the-art models for communicative teaching (Benati 2013) share commonalities reflected in the ATW online course. The authentic nature of the materials in ATW supports the importance of connecting the content of computer-based courses to the real world inhabited by teachers and learners. There are opportunities for "focus on form" (Ellis 2015) through developing awareness of grammar points, vocabulary, and genre-based discourse structures (Bhatia 2014; Pongsiriwet 2001; Schleppegrell and Christie 2018; Tardy 2016). The website is consistent with principles of communicative language teaching and learning (Hinkel 2017) in that it provides richly contextualized examples and carefully scaffolded experiences via real-world texts of speeches, readings, poetry, music, and lyrics.

\subsection{Language Learning and Peace Education}

Our research sought to promote a culture of peace and human rights through the acquisition of English as a global language with content focusing on the UN's activities worldwide. The content of the site and its association with the culture of the UN and its goals and activities make it culturally grounded (Furstenberg et al. 2001), so that the constructs of improving people's lives and working for peace are central to the values promoted in the lessons, tasks, resources, and artifacts.

Crystal (2004) stresses the importance of including environment, development, and human rights in a global curriculum for teaching peace. L2 teaching and learning is particularly appropriate for peace education, as issues of cultural diversity and intercultural communication must be represented in a communicative L2 curriculum and ideally should promote learners' awareness of their world. In addition, an acceptance of linguistic differences in others and ourselves must include an appreciation of and respect for alternative varieties of language. The ATW section on language variation addresses these issues for learners who may be marginalized because their speech is considered nonstandard (Nero and Ahmad 2014). An important aspect of language and peace education is the development of an appreciation for human inter-relatedness, global citizenship, and all that entails. ATW seeks to encourage learners to see the world through others' eyes. Furthermore, while English is acknowledged as a lingua franca for international trade and power, it also has potential as a language of wider communication to be a vehicle for peace and understanding. Language and peace education via technology is under-researched at this time and results will support further development in the field.

\subsection{Technology and Language Learning}

Technological development continues to challenge second language teachers and materials developers to integrate innovations into their curricula. Studies indicate that incorporating technology in L2 settings can enhance language learning (Moore 2009). Effective use of technology can promote critical thinking and facilitate social integration, communication, and cooperation in language classrooms (Osborn 2006). Instructional technology also encourages student-oriented approaches in L2 pedagogy and supports students' developing expertise in computer use (Warschauer et al. 2004).

While the potential value of technology for language learning is often discussed, language teachers and learners can be challenged and overwhelmed by the Internet explosion and the sheer variety of instructional technology currently available. Also of relevance is the concurrent move to a more dynamic, learner-centered curriculum that seeks to foster active learning and critical thinking (Kim 2008). In fact, the Internet makes collaborative learning possible globally. Chatel (2002) demonstrated the benefits of using the Internet for promoting literacy and higher order thinking. Chapelle (2005) and Chapelle and Jamieson (2008) suggest concrete research-based advice for using technology in L2, including multiple modes of input, programs that offer feedback to learners, explicit grammar instruction, and addressing pragmatic competence. 
However, despite the rich possibilities, technology integration in language learning is inconsistent and dependent on many factors. In light of our current knowledge and evolving challenges, continued research on more effectively incorporating technology in language pedagogy is needed (Kuure et al. 2016; Luke and Britten 2007). And while limited access to resources remains a major roadblock to the use of technology in the classroom (Ebsworth et al. 2010), individual access to the Internet continues to rise (Dumitrescu 2014). The ATW website lends itself to blended uses in which technology can supplement a teacher-led course but can also be used independently outside the classroom in settings such as the home, library, or community center.

\subsection{The Role of Consultants}

We aimed to advance the understanding of acquiring a second language through a technology, content-based, and project-oriented approach in a high school context, while encouraging a sense of self-efficacy among ELLs in promoting peace and wellness as well as supporting greater academic success (Asakereh and Yousofi 2018; Honicke and Broadbent 2016). An additional dimension of this research involved having learners take on the role of consultants to the project. Giving these students a more active part in this research context may encourage other researchers/educators to do likewise. The impact of this work ranges from L2 curriculum development and matching technology to learner needs and interests to a re-examination of student and teacher roles in the classroom.

\section{Materials and Methods}

Inspired by a transformative action research paradigm (Savin-Baden and Major 2013), a mixed design (Creswell 2007; Mackey and Gass 2016) was used to evaluate ATW in an American high school setting. We investigated the effect of using ATW on the academic English development of ELLs and elicited their views on how the course can be made more attractive to adolescents. We also hoped the students would be inspired by the efforts of the UN to promote health and peace worldwide.

Student participants acted as "consultants" for the project. All students and parents gave their informed consent for inclusion before they participated in the study. Prior approval for the protocol was granted by NYU (IRB \#FY2016-596) and the NYC Dept. of Ed. (\#1372). Although the setting for the study was an English language arts class composed completely of ELLs, the content was found to be appropriate by the teacher as useful for the kinds of academic receptive and productive experiences that would aid the students' literacy development; they read, discussed, and wrote about the topics presented in each unit they worked on. ATW uses relatively simple multimedia technology so that it can be accessed by individuals in different parts of the globe, who may have limited technological possibilities. Since ATW was originally developed for adult users, we had a concern that young digital natives might require a more sophisticated approach.

Nineteen volunteer English learner/consultants began using the site with guidance from the teacher and student teacher, Melissa (pseudonym).

\subsection{Research Questions}

1. What are the adolescent consultants' perceptions regarding the usefulness of units and activities of ATW for improving their ESL skills?

2. To what degree does the unit content confirm, and/or challenge learners' understandings of the role of the UN around the world?

3. What is the role of technology in the ATW online course in promoting the learning of language and/or content?

4. What are the teacher's perceptions regarding the use of ATW with her students?

5. What improvements and/or revisions to ATW in content and technology are suggested by the insights gleaned from the consultants and their teacher? 


\subsection{Researchers}

Miriam Eisenstein Ebsworth is an English-dominant polyglot who taught ESL to elementary learners in the New York public schools. Subsequently, she taught academic English to ESL and English as a Second Dialect undergraduate learners at Rutgers University in Newark, NJ and has taught graduate courses in language education at New York University for over 35 years. She acted as a consultant in developing the ATW online course.

Chencen Cai is a doctoral student in TESOL who is polylingual, with a command of Mandarin, Guilin dialect, Cantonese, and English. She in an experienced language teacher, having taught English in China and both Mandarin and ESL in the US.

Lauren McCoy is bilingual, with fluency in English and Spanish, and is currently a doctoral student in the Department of Curriculum and Teaching at Teachers College, Columbia University. She teaches ENL (English as a new language) and AP (Advanced placement) English at a New York City public school for emergent bilinguals.

\subsection{Student Participants}

Nineteen student volunteers (all students in the class elected to participate) acted as student consultants in our project. They represented 6 Latin-American countries (Columbia, The Dominican Republic, Ecuador, Guatemala, Honduras, and Mexico) as well as Puerto Rico, a Commonwealth territory of the US. All students were native Spanish speakers demonstrating a range of English proficiency. An English test developed locally was administered before the class and identified their proficiency levels as follows: Low intermediate (1), Intermediate (6), High Intermediate (10), and Advanced (2). These levels are equivalent to the ACTFL (American Council on the Teaching of Foreign Languages) proficiency guidelines (ACTFL 2012).

Students' time spent on the computer was as follows (See Table 1):

Table 1. Hours spent on computer per week.

\begin{tabular}{ccc}
\hline & Frequency & Percent \\
\hline $0-10$ hours & 18 & 94.7 \\
41+ hours & 1 & 5.3 \\
Total & 19 & 100.0 \\
\hline
\end{tabular}

This contrasted with more time spent on the cell phone (See Table 2).

Table 2. Hours spent on cell phone per week.

\begin{tabular}{ccc}
\hline & Frequency & Percent \\
\hline $0-10$ hours & 4 & 21.1 \\
11-20 hours & 3 & 15.8 \\
21-30 hours & 4 & 21.1 \\
31-40 hours & 6 & 31.6 \\
41+ hours & 2 & 10.5 \\
Total & 19 & 100.0 \\
\hline
\end{tabular}

Thus, all of the students had previous online experiences. Almost all students used online devices or social media platforms for fun. About half reported using online resources for learning out of the classroom. Eighteen mentioned devices other than computer or cell phone, 12 provided examples of social media platforms used for fun, and 14 provided examples of online learning tools.

\subsection{Class Description}

The class was offered for $40 \mathrm{~min}$ from Monday to Friday during the fall 2017 semester. The teacher met with the first two authors to collaborate on how to integrate the website into her class. Erin and 
Melissa were both fluent in Spanish and available to offer first language support when the students were using the website. Researchers/observers also offered guidance when requested. One of the goals of the ESL class was to build reading stamina and academic writing in English. At the same time, Erin noted the need to promote students' language development through explicit and targeted grammar and vocabulary instruction.

Erin integrated the units from ATW throughout her existing curriculum to meet these course goals. About $25 \%$ of the class involved direct use of ATW, although many additional enriching activities were developed by the teacher. At the time of the study, students were reading various short works of fiction and a novel centering around the themes of tolerance, peace, and social justice. These themes continued to be highlighted throughout the ATW work. At various points throughout the semester, Erin organized a stand-alone lesson using ATW and connected the ATW unit back to themes from students' previous readings. Erin developed questions and discussions to offer helpful background in advance and follow-up assignments to support learners' English oral and writing development. Students were encouraged to read and comment on each other's work in order to develop a community of learning and raise their awareness of how ideas could be expressed through oral and written language. A translanguaging approach was encouraged in oral exchanges.

Erin started with Unit 1 of ATW, which provided an overview of the UN and its work. In this and subsequent lessons, Erin chose units that she thought would match students' interests and previewed each unit with an activity to evaluate and develop prior knowledge. They sat in small groups and would read the text, either independently or in pairs, answering reading comprehension questions from the unit and/or teacher; they then worked independently through the grammar lesson and other activities. Differentiated tasks assigned to students reflected their English proficiency at the time of the assignment. When the teacher used ATW in the class, because of the various English proficiency levels in the class, she encouraged students to go ahead in the lesson at their own pace or proceed to other lessons if they finished early. For students who needed extra support, she encouraged the use of Google Translate, online bilingual dictionaries or glossaries, and the Internet to search for more information.

At the end of each lesson, Erin collected any associated student work she had developed and facilitated a whole-class discussion on things students had learned and/or still had questions about. In one of the final lessons with ATW, students chose a unit on their own.

\subsection{Data Sources}

Monthly classroom observations were conducted. Researchers not only observed and took field notes but also periodically participated as support resources for students while they were working on ATW. Our interactions added to our understanding of the students' process in using the site. Additional data came from "pre" and "post" questionnaires, student essays, and semi-structured interviews with 8 student volunteers. Questionnaires contained quantitative queries, using Likert scales, and open-ended qualitative questions. Pre- and post-questionnaires were brief given the limited time available. Questions came from preliminary discussions with teachers and administrators and were piloted with other students to be sure the questions were clear and relevant. Essays were assigned by the teacher as discussed in the class description (above). Interviews were audio-recorded and lasted from 10 to 15 min. Interviewers included the PI (Principal investigator), two RAs (Research assistants), the student teacher, and a visiting scholar. The PI is fluent in Spanish, which allowed for translanguaging to encourage interviewees to call upon all of their linguistic resources in order to fully express themselves. The teacher was interviewed at the beginning, midpoint, and end of the semester-long project. These semi-structured interviews explored her understanding of how participating in the ATW online course may have influenced her teaching practice as well as her students' English acquisition, technological awareness, and sense of community engagement. (See Appendices A-D for sample questionnaires and interview protocols.) Every data source contributed to the answer to each of the research questions. 


\subsection{Analysis}

Each data source was analyzed following a constructivist grounded theory framework (Charmaz 2014). Interviews were transcribed, translated when necessary, and themes identified through a recursive process of analysis (Savin-Baden and Major 2013). Triangulation of data interpretation (Leech and Onwuegbuzie 2007) included the perspectives of the researchers, an expert in language and technology, and a sample of participants representing a range of backgrounds, cultures, and experience with technology.

\section{Results}

\subsection{Descriptive Comparison of Quantitative Items from Pre-and Post-Questionnaires}

Overall, students began with a rather positive view and developed an even more optimistic sense of the work done by the UN. However, regarding UN work with children, they declined slightly (See Table 3). (Post participant numbers were lower due to absences on the day that data were collected.)

Table 3. Quantitative items from pre- and post-questionnaires.

\begin{tabular}{lll}
\hline \multicolumn{1}{c}{ Item } & Pre $(\boldsymbol{N}=\mathbf{1 8})$ Mean $(\mathrm{SD})$ & Post $(\boldsymbol{N}=\mathbf{1 4})$ Mean (SD) \\
\hline 1. Promoting world peace & $3.67(0.77)$ & $3.69(0.86)$ \\
2. Helping countries with health and wellness & $3.72(1.07)$ & $4.15(0.99)$ \\
3. Helping with education & $4.17(0.71)$ & $4.38(0.87)$ \\
4. Protecting and supporting children worldwide & $4.28(0.90)$ & $4.00(1.00)$ \\
\hline
\end{tabular}

Based on what you know about the UN, how effective do you think it is at doing the following: $(1=$ very ineffective; 2 = somewhat ineffective; $3=$ neutral; 4 = somewhat effective; 5 = very effective).

\subsection{Open-Ended Comments from the Post-Questionnaire}

While at the beginning, students had little specific knowledge regarding the United Nations, they developed a much more elaborated sense of the range of roles performed by the UN. "The UN stop war from happening." "The UN does it keep the people safe from world and country problems." "It helps us to know about the different cultures around the world." "Help countries to unite and be with peace." "UN Protects the heritage places."

\subsection{Student Themes}

The following student themes (presented with corresponding research questions noted) emerged from interview data and from the open-ended aspect of the questionnaires. All comments quoted below come from the interview data. Students appeared highly engaged throughout this project and offered thoughts and suggestions in a serious and constructive way. Where appropriate, comments recorded from observations and informal conversations were used to confirm interview interpretations.

\subsubsection{Positive Overall View of Online Course (RQ1)}

All interviewees offered essentially positive reflections regarding ATW: "I think it's good. I like the information and how they present the (information)." "I really like the organization, and the information that it contains, and the activities."

\subsubsection{Importance of Visuals for Teens (RQ1, 3)}

As the original website was constructed for an adult user, it is not surprising that the adolescent consultants focused on the importance of visual support in general and the need for more videos in particular. "Like for us teenager, it's better to see than to read it sometimes; I expect like more pictures and videos." "I think sometimes teenagers are lazy. They more like videos and pictures that explain what's happening." 


\subsubsection{Gaps in Background Knowledge (RQ2)}

All adult participants observed that the students lacked much of the general knowledge presumed to be shared by US-born middle-class high school students. This was confirmed by the following typical interchange: "How much of the information was new to you?" "Everything!"

\subsubsection{Vocabulary Support Helpful (RQ1, 3)}

While becoming aware of the lexicon of an additional language is certainly central, it was interesting to note that virtually all students commented on the usefulness of the vocabulary section offered in each unit and how they made use of it. "Sometimes there are words that I (don't) understand, but they have their vocabulary (list). That's kind of good because it helps me." "Of the vocabulary section ... I click on the link." Finally, students recognized the importance of low-frequency academic language. "Of the vocabulary section, it helps you a lot with the words that are not used a lot in our vocabulary."

\subsubsection{More Grammar (RQ1, 3)}

Several learners commented on their appreciation of the grammar focus in each unit. In fact, a few interviewees said they would like even more. "I think it would be good to have more grammar." "I like the grammar test, something like more activities like that."

\subsubsection{Strategies When They Do Not Understand (RQ1, 3)}

Since the class was composed of students with a broad range of English proficiency, there were substantial comprehension challenges for many of the learners. "I did not understand all of the English." "The reading selection was too long and too hard for me." But without exception, each had developed strategies to deal with this problem. The student community had established a shared set of strategies, perhaps reinforced by the teacher. The following examples are typical: "First, you have to read the whole sentence ... If you don't know, then get a dictionary ... with Spanish." "And for the computer, I Google it."

\subsubsection{Mixed Views Regarding Peer Support (RQ1)}

Several students offered that being able to call on peers was helpful to them. "Yeah, usually most of my friends know a lot of English. There are words that I don't understand, but they do. So I ask them for translation." "When I'm writing something, I don't know how to spell the word, I ask my friends first." However, a few students preferred not to ask their friends for help or did not have confidence in their peers' knowledge. "I don't ask friends; I just do it by myself or ask my teachers." "If I'm not convinced with them (peer suggestions), I ask my teacher." "I don't ask my friend about work; I guess I figure it out by myself."

\subsubsection{Preferred Language of Explanation (RQ1)}

Students typically expressed that both English and Spanish were useful, rather than identifying a preference for one or the other. "Sometimes Spanish translation is helpful." "Sometimes they tell me the definition (in English); I still don't understand. If they say in Spanish, it's easier for me to understand." "I ask our teacher that talks Spanish and English so that they can try to help me with both languages."

\subsubsection{Recognition of UN Contribution (RQ2)}

Many of the students interviewed offered examples of UN programs. "They travel around the world trying to help the countries conquer the peace that they want... and help them with the problems." They appreciated the UN role in promoting ecology. "Help keep natural beauty of a great deal of countries." Students also praised the help offered by the UN to those in need. "Help a lot of 
people in bad situations." Finally, several students expressed surprise but also appreciation in that the UN "protects the heritage places."

\subsubsection{Technical Issues (RQ3)}

The need to both update the current ATW site and also adapt it to the restrictions and realities of urban high school classrooms was ubiquitous in students' comments. For example, "The technology did not always work." "Problems ... the page is really well done, but sometimes when you are trying to get in, it doesn't really work." "We can't get YouTube from school and other links are blocked or not there."

Thus, students reflected that they encountered some technical issues when trying to click on some links on the website or use certain social media functions. In class, some of the student participants accessed alternative websites to search for information regarding the focus of the unit. Additionally, as some limitations on access of particular websites were imposed by the school district, workarounds were needed.

\subsubsection{Appreciation of Consultant Role (RQ1)}

"I liked taking the role of consultant to help improve the website." The teacher, Erin, also confirmed that students were excited to be active participants in our project. In a final ceremony, students were delighted to receive a certificate of appreciation for their contributions as well as a small thank-you gift. Erin also noted that this experience would enhance their college applications.

\subsubsection{Favorite Units (RQ1, 2)}

While all students expressed general approval of the website, two of the units were particularly attractive to learners, as follows: Topic on Peacekeepers: "I learned that they are the ones that are ensured of keeping peace all over the world."; and World Heritage Sites: "I think that the United Nations helps to protect the natural and cultural beauty all around the world like the most beautiful places or natural places." Students also felt that ATW had given them expanded interest in new places "I think Venice, Italy. I like it."

\subsubsection{Recommendations for Change (RQ5)}

Several ideas were salient in students' commentary on how ATW could be improved for adolescent English learners. "More games! I enjoy the games very much." "Make more user friendly for teenagers, like videos and photos." Interestingly, there were several comments from students recognizing the need to make ATW more useful for differentiation of instruction. "I think we should make it better... like putting more easy words that we can understand." "There should be different levels for reading." "Have versions of readings in other languages." "I think they could give more examples about history so we can learn more (about that)."

\subsection{Teacher Themes (RQ4)}

Erin's reflections included views of the practical challenges of using the technology in her school, the complexity of working ATW into her curriculum, the limitations of available classroom time, and the degree to which support for ATW was needed so that the student consultants could gain maximum benefit from the site.

\subsubsection{The Unit Was More Challenging for Learners than Expected}

As is often the case, teachers must adjust their plans to classroom realities. "I thought students would be able to go through the unit more independently than what they did." Observations and interactions with researchers confirmed that that many of the students required help from peers, the 
teacher, student teacher, or researchers, both to understand the English language and also to provide needed background knowledge.

\subsubsection{There Are Practical Barriers to Using the Site in My Classroom}

"The district blocks YouTube and social media. This limits what I can do." Erin noted that in light of the short time allotted for her class, she needed to shift some use of the ATW site to out-of-class activities. "Students were encouraged to explore at home." There were also sometimes limitations on the numbers of working computers available for the class. The teacher had to accommodate to this situation. "Due to computer availability, students worked in groups. Also, for some activities, some students were given related paper-based tasks while others used the Internet."

\subsubsection{Gaps in Background Knowledge}

The researchers, teacher, and student teacher all noticed that as also reflected in the student interviews, the English learners appeared to lack general information about local and international politics, history, economics, geography, and other content knowledge expected for high school students to have acquired either through previous educational or social interaction. "There are so many things they need to know but they haven't been exposed to... And a lot of students have gone back and forth from home to the US-the quality of the school is dependent on socioeconomic factors ... So some kids get an excellent education, but others don't." Erin was particularly sensitive to the challenges of circular migrants. "The circular migrants keep losing out... Education can be spotty-their lives can be like the lives of migrant workers in the sense that they don't have continuous school-the quality of the school is dependent on socioeconomic factors."

\subsubsection{Suggestions for Pedagogy}

Erin always considered how to move students forward considering where they started from and had a dynamic view of teaching and learning. "What does the teacher do? Just keep building on what they have ... and then using their interest to give them something to connect up." "Keep updating the site in terms of content." Erin also confirmed that the level of technology did not seem to be an issue. "I don't think the lack of bells and whistles has been a problem ... It's more about text complexity, the length, the size of the text, even the font." She was pleased at the level of personal control students could exercise. "What I like about the ATW website is that they can build on what they know, and click on those links and further explore things ... they can work at their own pace."

\subsubsection{Need for Differentiation}

This theme resonated with Erin as well as the learners; she addressed the challenge of teaching a class with mixed levels, a very common situation when teaching ELLs. "More differentiation is needed." "If this unit is to be used instructionally in this class, I will need to differentiate the reading materials and grammar points, as well as some of the writing tasks throughout the unit."

Although Erin commented, "I did not really have work differentiated," in our observations, we noted that she was actually very flexible in the nature of feedback and support she offered, adjusting her relative use of first and second languages and the degree to which her response required students to act more or less independently in finding answers to their queries.

\subsubsection{Clarifying Goals and Integration in Regular Lessons}

Erin stated, "In my planning, I see that I need a clear, manageable objective." And she also commented, "After reflecting on the lesson before the (holiday) break and the feedback that the students gave ... I wanted to use a unit to meet instructional goals; that is, I wanted to use the site as a resource in a more traditional lesson with a specific content and language objective." Erin 
experienced time constraints as she added ATW to her curriculum. "Sometimes going through a unit felt a bit rushed. I could see designating maybe two weeks to thoroughly go through one unit."

Erin is a reflective teacher, and her interviews and asides showed that she was constantly revising and reformulating her teaching to accommodate insights regarding learners and outcomes as they emerged.

\subsubsection{Independent Use of Site versus Guided In-Class Use}

Erin talked about the fact that some students were more able to use the site independently than others in class. "For the high school level: If it is for students to do independently, then I think our target ELLs may be more advanced than some of the students in this group." "Some of my more advanced students in the class were able to work independently through the materials." Regarding less proficient speakers, Erin suggested, "They can still work on the technology piece-something from the unit but more limited."

\subsubsection{Future Projects}

Erin commented on an important future step planned for our student consultants. "We'll need to work together to map out ... projects the students might do to help their communities ... inspired by this experience." In fact, MMHS requires that each student engage in community service. We are hopeful that these experiences will be inspired by what students have learned about the work of the UN.

Erin also suggested that for the future, a teachers' manual would be a potentially helpful addition to the online course. "Maybe develop a teacher's manual to use the site ... How to deal with problems that can come up..."

\subsection{Researcher Themes $(R Q 3,5)$}

Based on our class observations and interactions with students and teachers, we noticed some issues related to the students' learning process and the teacher's pedagogical strategies. Many of our insights are consistent with the themes presented above.

\subsubsection{Student Strategies in Making Meaning}

When students encountered difficult text, they often used web-based tools to help with their reading comprehension. For example, "in the first class, we observed that some students copied and pasted some text into Google Translate. One student put on his headphone and listened to the audio text."

\subsubsection{Differentiation Observed}

In the class, we noticed several differentiation strategies that were effective to support students' learning needs at different levels. These included homogeneous grouping and scaffolded tasks. The teacher also encouraged students to consult each other and search the Internet for information they needed.

\subsubsection{Peer Support}

Some students asked each other for help and discussed what was happening in the group. They developed strategies on their own to help them learn. Such behavior was encouraged by Erin, in creating a community of learning. This class was rarely silent, but our observations indicated that student voices nearly always reflected engagement with the task and topic at hand. 


\subsubsection{First Language Support}

Bilingual teacher facilitators provided help to students. The teacher, student teacher, and PI are fluent in Spanish and English. This was a class in which all participants were encouraged to use a translanguaging approach in order to enhance learners' and facilitators' abilities to maximize communication by calling on all linguistic resources available.

\subsubsection{Learner Differences in L1 Academic Proficiency and Cultural Knowledge}

Through observations and interactions, it became clear that in addition to differences in English proficiency, there was substantial variation in the first language academic preparation of the students and in their general knowledge, as has been noted in all data sources. It will be important to continue to explore avenues for differentiating input and activities to account for such student diversity.

\section{Discussion}

Data from observations, questionnaires, and interviews with the student consultants and teacher indicate that overall, they were satisfied regarding the usefulness of the ATW online course for improving English and acquiring knowledge about the United Nations and other countries around the world. Student and teacher suggestions for revision to make the site friendlier for adolescent learners include a more fine-tuned assessment at the start to identify areas in need of development, more visuals, games, differentiation of instruction via alternative texts, and access to first and second language support through hyperlinks.

The creation of a class atmosphere in which students were encouraged to resolve challenges creatively through computer searches and peer support contributed to the successful implementation of this project. While students were inspired to act independently and collaboratively, Erin also was prepared to step in and offer approaches for students to answer their own questions, while being prepared to give answers herself when she deemed it appropriate. Thus, this teacher was highly effective in balancing the power of technology to engender student-centered learning (Granberg 2000) while providing direct input when she judged that was what students needed.

The gaps in background knowledge for the ELL population of the class presented both a challenge for comprehension and an opportunity for learners to be exposed to this important information. Hirsch (2013) refers to this assumed background knowledge as cultural literacy, and this has been identified as a hidden requirement for high school students' full participation and academic success. At the same time, the multicultural nature of ATW provided for the ELLs to draw on the information they could retrieve from their own sociocultural experiences, allowing the class to reflect a "Funds of Knowledge" approach (Moll et al. 1992), crediting multicultural learners with the unique background each could offer to enrich the class and support their learning. The movement to make learning student-centered and culturally sensitive echoes this issue, calling for a focus on learners' cultural backgrounds when drawing on the affordances of technology, goals that should be considered in future development and pedagogy (McDermott 2017).

An additional factor that enhanced students' learning and communication as well as their abilities to maximize their understanding of ATW was the encouragement of translanguaging through peer, facilitator, and teacher support in the classroom. Such translanguaging is distinguished from code-switching in that it frames linguistic resources in a holistic rather than a dichotomous fashion. "Translanguaging is the act performed by bilinguals of accessing different linguistic features or various modes of what are described as autonomous languages, in order to maximize communicative potential" (García 2009, p. 140).

Practical limitations in terms of availability of computers and working around sites blocked by the school were addressed by the teacher through creative alternatives and home-based assignments. Fortunately, the school administration was very supportive and also offered technology support to assist with this and other logistical challenges that arose. Recent advances of Internet resources to 
support learning language through content have added many possibilities. For example, TOOLS (n.d.), a free online tool, designed to support CLIL teachers and curriculum developers is ongoing, interactive, and available for free.

There is also evidence to indicate that some learners became more aware of social justice issues, sparked by the content of the units. One student, queried, "Why is there poverty in countries that have natural resources?" In an interview, Erin reflected, "He really didn't know that. It's a good question. He is from a relatively poor country and is unaware of the answer to that question ..." She also addressed the diversity in the level of education different students bring to her class. "So some kids get an excellent education, but others don't." The next step for learners, developing a community-based project inspired by the work of the UN, involves the forthcoming stage of this action research.

An unexpected finding was that the adolescents in our study highlighted and appreciated the vocabulary development and grammar support offered within each unit. While these aspects of language teaching exist in traditional classes and paper-based texts, it was interesting that they were not taken for granted by our student consultants. Indeed, the affordances of technology can be harnessed to promote the learning of lexical items in context and grammatical aspects of language also extracted from contextualized sources. This demonstrates that "focus on form" for learners is not only recommended by the literature (Mackey 2006) but is seen as desirable by adolescent language learners. In the literature on developing grammatical awareness, a distinction is drawn between "focus on form" which occurs organically as issues arise, taking advantage of the cognitive window that is activated when an issue of grammar comes up in classroom discourse, and "focus on forms" which reflects a previously-planned activity considering a grammar point deemed appropriate for a class or individual both in developmental and communicative terms (Long and Robinson 1998). In a sense, ATW allowed for both aspects of grammatical awareness. Units contained grammar items and exercises that were planned in advance (focus on forms). The technology allowed students the option of choosing to access such information and participate in the practice when they felt a need to do so on the spot, adding to their abilities to take charge of their own learning. Finally, as ATW was used in the class discussed here, students might request support from a facilitator when they encountered a structural item they did not feel secure they could understand and/or use (focus on form).

\section{Conclusions}

A synthesis of our findings demonstrates the fact that although ATW has not yet incorporated the highest level of technology available, the English learners in our study found it both helpful and engaging. Indeed, the original site was designed to be accessible for a broad population worldwide, and so the designers balanced the most up-to-date technological possibilities with hardware and software that were widely available. Despite our concern that teenagers, as digital natives, might be put off by the lack of state-of-the-art applications and platforms in the current version of ATW, they were able to concentrate their attention on the information offered and appreciate the opportunity to guide their own learning through personal choices, hyperlinks, and multimedia elements incorporated in the site.

A promising aspect of this study, worthy of further research, is the transformative potential of the consultant role taken by the English learner volunteers. "Learning is not a product transmitted from the more knowledgeable party (the teacher/instructor) to the less knowledgeable party (the students). Rather, from a constructivist point of view, learning is achieved in an environment in which the student is at the center of the learning process, and the role of the teacher is to act as a learning facilitator." (Hamdan 2014, p. 319).

At the end of the course, students expressed pride in their participation and achievement. An unintended outcome was students' success with a statewide English examination required for high school graduation. We were pleased to learn that all our student consultants who took this exam passed it. Future research could examine the role of ATW in supporting academic English development and general knowledge among students such as those in our study. 
Additional future directions for development of our online course include extending hyperlinks to incorporate recent updates to the UN website as well as language-based digital tools and strategies as they continue to evolve in this dynamic and developing environment. Finally, a more long-term goal is to work on a mobile phone app that will make ATW even more accessible for learners around the globe.

Author Contributions: Conceptualization, M.E.E.; Data curation, C.C.; Investigation, M.E.E., C.C., and L.M.; Methodology, M.E.E.; Project administration, M.E.E.; Software, C.C.; Supervision, M.E.E.; Validation, C.C.; Writing-original draft, M.E.E. and C.C.; Writing-review and editing, M.E.E., C.C., and L.M.

Funding: This research was funded by a New York University Steinhardt Professional Development Grant.

Acknowledgments: The encouragement and collaboration of the principal, vice principal, teacher, and student volunteers and faculty of MMHS were critical in making this project possible. Appreciation also to Patricia Duffy, the Principal Developer of the ATW Website and faculty of the UN Language Programme. The Webmaster was ESL Specialist and consultant, Jill Kalotay. Research assistants Huay Chen, Chairin Lim, Gabriela Abramac, and Brianna Avenia-Tapper also contributed to the project.

Conflicts of Interest: The authors declare no conflict of interest.

\section{Appendix A Sample Pre-Questionnaire for Students}

\section{Name}

Class

\section{Grade level}

I. Tell about your experience using the Internet.

a. Every week, I spend about __ hours a week online on the computer. I spend about __ hours a week online using a cell phone.

b. My total time online is spent:

For fun? __ hours a week. (give an example, such as a game you might play)

c. For learning (not in class)? hours a week (for example, doing homework or other learning)

For English language learning (not in class)? hours a week

For learning in class (if applicable)? hours a week

II. I enjoy learning online.
1. Agree strongly;
2. Agree;
3. Neutral;
4. Disagree;
5. Disagree Strongly

III. Based on what you know about the United Nations, how effective do you think it is it at doing the following (please circle your opinion):

a. Promoting world peace

1. Very ineffective; 2 . Somewhat ineffective; 3 . Neutral; 4 . Somewhat effective; 5 . Very effective

b. Helping countries with issues of health and wellness

1. Very ineffective; 2 . Somewhat ineffective; 3 . Neutral; 4 . Somewhat effective; 5 . Very effective c. Helping with education

1. Very ineffective; 2 . Somewhat ineffective; 3 . Neutral; 4 . Somewhat effective; 5 . Very effective d. Protecting and supporting children around the world

1. Very ineffective; 2 . Somewhat ineffective; 3 . Neutral; 4 . Somewhat effective; 5 . Very effective

Can you think of anything else the UN does?

IV. Rate your English skills right now:

Oral comprehension

1. Beginner; 2. High Beginner; 3. Intermediate; 4. High Intermediate; 5. Advanced

Reading comprehension

1. Beginner; 2. High Beginner; 3 . Intermediate; 4. High Intermediate; 5. Advanced 
Speaking fluency

1. Beginner; 2. High Beginner; 3. Intermediate; 4. High Intermediate; 5. Advanced Writing

1. Beginner; 2. High Beginner; 3. Intermediate; 4. High Intermediate; 5. Advanced

V. In addition to your collaboration as a consultant on the UN Project, what do you hope to learn for yourself?

a. I want to improve my English skills.

1. Agree strongly; 2. Agree; 3. Neutral; 4. Disagree; 5. Disagree Strongly

b. I want to learn more about the United Nations

1. Agree strongly; 2. Agree; 3 . Neutral; 4. Disagree; 5. Disagree Strongly

VI. How do you feel about the following?

a. I believe that we can work successfully to improve life for people in my community in the US.

1. Agree strongly; 2. Agree; 3. Neutral; 4. Disagree; 5. Disagree Strongly

b. I believe that we can work successfully to improve life for people in my community in my home country.

1. Agree strongly; 2. Agree; 3. Neutral; 4. Disagree; 5. Disagree Strongly

c. I believe that we can work successfully to improve life for people in other parts of the world.

1. Agree strongly; 2. Agree; 3. Neutral; 4. Disagree; 5. Disagree Strongly

Appendix B Sample Post-Questionnaire for Students

Name

Class

Grade level

Based on what you know about the United Nations, how effective do you think it is it at doing the following (please circle your opinion):

a. Promoting world peace

1. Very ineffective; 2 . Somewhat ineffective; 3 . Neutral; 4 . Somewhat effective; 5 . Very effective

b. Helping countries with issues of health and wellness

1. Very ineffective; 2 . Somewhat ineffective; 3 . Neutral; 4 . Somewhat effective; 5 . Very effective

c. Helping with education

1. Very ineffective; 2 . Somewhat ineffective; 3 . Neutral; 4 . Somewhat effective; 5 . Very effective

d. Protecting and supporting children around the world

1. Very ineffective; 2 . Somewhat ineffective; 3 . Neutral; 4 . Somewhat effective; 5 . Very effective

Can you think of anything else the UN does?

\section{Appendix C Sample Interview Questions for Students}

1. Tell me a little about your experience using the Internet.

For fun? For learning? In class?

For English language learning in particular?

2. Tell me about using the Actionthroughwords online course. (Probe for clarification and examples)

3. What do you think about the content on the UN work for health and peace?

4. What if anything did you learn from the site that you think helped with your English?

5. We want to know how this site could be made more user friendly for teenagers.

What are your suggestions? What did you like? What changes would you suggest?

6. We want to know how this site could be more helpful for English learners.

What did you find helpful? What are your suggestions for improvements in the site?

7. What ideas occurred to you about how you might help your community or others around the world?

8. Is there anything you'd like to add? 
9. Do you have any questions for me?

\section{Appendix D Sample Interview Questions for the Teacher}

1. Tell me a little about your experience using the Internet.

For yourself? For your students? In class? As an out-of-class resource?

For English language learning in particular?

2. Tell me about using the Actionthroughwords online course with the volunteer students. (Probe for clarification and examples)

3. What do you think about the content on the UN work for health and peace? Did you get any sense of how the students reacted to that?

4. What if anything did they learn that you think helped with their English?

5. We want to know how this site could be made more user friendly for teenagers.

What are your suggestions? What did your students like? What changes would you suggest?

6. We want to know how this site could be more helpful for English learners.

What did your students find helpful? What are your suggestions for improvements in the site?

7. What if anything do you think you could do to facilitate students' engagement with their community or others around the world?

8. Is there anything you'd like to add?

9. Do you have any questions for me?

\section{References}

ACTFL. 2012. ACTFL Proficiency Guidelines. Available online: https://www.actfl.org/sites/default/files/pdfs / public/ACTFLProficiencyGuidelines2012_FINAL.pdf (accessed on 31 January 2019).

Allwright, Dick, and Judith Hanks. 2009. The Developing Language Learner: An Introduction to Exploratory Practice. In Research and Practice in Applied Linguistics. Basingstoke: Palgrave Macmillan.

Asakereh, Ahmad, and Nouroddin Yousofi. 2018. Reflective Thinking, Self-Efficacy, Self-Esteem and Academic Achievement of Iranian EFL Students in Higher Education: Is There a Relationship? International Journal of Educational Psychology 7: 68-89. [CrossRef]

Benati, Alessandro. 2013. Issues in Second Language Teaching. Sheffield: Equinox.

Bhatia, Vijay. 2014. Analysing Genre: Language Use in Professional Settings. New York: Routledge.

Canagarajah, A. Suresh. 2013. Translingual Practice: Global Englishes and Cosmopolitan Relations. New York: Routledge.

Chapelle, Carol. 2005. Hints about CALL Use from Research. PacCALL Journal 1: 1-8.

Chapelle, Carol, and Joan Jamieson. 2008. Tips for Teaching CALL. White Plains: Pearson Education ESL.

Charmaz, Kathy. 2014. Constructing Grounded Theory. Los Angeles: SAGE.

Chatel, Regina G. 2002. New Technology, New Literacy: Creating a Bridge for English Language Learners. New England Reading Association Journal 38: 45-49.

Commission of the European Communities. 2003. Communication No. 449. On Promoting Language Learning and Linguistic Diversity: An Action Plan 2004-2006. Available online: https:/ / eur-lex.europa.eu/LexUriServ/ LexUriServ.do?uri=COM:2003:0449:FIN:EN:PDF (accessed on 5 December 2018).

Coyle, Do, Philip Hood, and David Marsh. 2010. CLIL: Content and Language Integrated Learning. Cambridge: Cambridge University Press.

Creswell, John W. 2007. Qualitative Inquiry and Research Design: Choosing among Five Approaches. Thousand Oaks: SAGE.

Crystal, David. 2004. Creating a World of Languages. Introductory speech presented at the 10th Linguapax Congress, Barcelona, Spain, May 20.

Daud, Nuraihan Mat, and Zamnah Husin. 2004. Developing Critical Thinking Skills in Computer-Aided Extended Reading Classes. British Journal of Educational Technology 35: 477-87. [CrossRef]

Doughty, Catherine, and Jessica Williams. 1998. Focus on Form in Classroom Second Language Acquisition. Cambridge: Cambridge University Press.

Dumitrescu, Virginia Mihaela. 2014. Effective Web 2.0 Technologies for Second-Language Teaching and Learning. Elearning $\mathcal{E}$ Software for Education 3: 148-55. 
Ebsworth, Miriam Eisenstein, Alexis Jeong Kim, and Tristin J. Klein. 2010. Projections: From a Graduate TELL Class to the Practical World of L2 Teachers. CALICO Journal 27: 349-75. [CrossRef]

Ellis, Rod. 2015. The Importance of Focus on Form in Communicative Language Teaching. Eurasian Journal of Applied Linguistics 1: 1-12. [CrossRef]

Furstenberg, Gilberte, Sabine Levet, Kathryn English, and Katherine Maillet. 2001. Giving a Virtual Voice to the Silent Language of Culture: The Cultura Project. Language Learning and Technology 5: 55-102.

García, Ofelia. 2009. Education, Multilingualism and Translanguaging in the 21st Century. In Multilingual Education for Social Justice: Globalising the Local. Edited by Ajit Mohanty, Minati Panda, Robert Phillipson and Tove Skutnabb-Kangas. New Delhi: Orient Balckswan, pp. 128-45.

Gimeno, Ana. 2008. How Can CLIL Benefit from the Integration of Information and Communications Technologies? In Linguistic Insights—Studies in Language and Communication. Edited by Maurizio Gotti. Bern: Peter Lang, pp. 77-102.

González, Norma, Luis C. Moll, and Cathy Amanti, eds. 2009. Funds of Knowledge: Theorizing Practices in Households, Communities, and Classrooms. New York: Routledge.

Granberg, Ellen. 2000. How Technology Enhances Teaching and Learning. Teaching Forum 3. Available online: https://cft.vanderbilt.edu/articles-and-essays/the-teaching-forum/how-technology-enhancesteaching-and-learning/ (accessed on 1 December 2018).

Hamdan, Amani K. 2014. The Reciprocal and Correlative Relationship between Learning Culture and Online Education: A Case from Saudi Arabia. The International Review of Research in Open and Distributed Learning 15: 309-36. [CrossRef]

Hinkel, Eli, ed. 2017. Handbook of Research in Second Language Teaching and Learning: Volume 3, 1st ed. New York: Routledge.

Hirsch, E. D. 2013. Cultural Literacy: What Every American Needs to Know. Ashland: Blackstone Audio Inc.

Honicke, Toni, and Jaclyn Broadbent. 2016. The Influence of Academic Self-Efficacy on Academic Performance: A Systematic Review. Educational Research Review 17: 63-84. [CrossRef]

Hubbard, Philip. 2008. CALL and the Future of Language Teacher Education. CALICO Journal 25: 175-88.

Kim, Hoe Kyeung. 2008. Beyond Motivation: ESL/EFL Teachers' Perceptions of the Role of Computers. CALICO Journal 25: 240-59.

Kuure, Leena, Tonja Molin-Juustila, Tiina Keisanen, Maritta Riekki, Netta Iivari, and Marianne Kinnula. 2016. Switching Perspectives: From a Language Teacher to a Designer of Language Learning with New Technologies. Computer Assisted Language Learning 29: 925-41. [CrossRef]

Leech, Nancy L., and Anthony J. Onwuegbuzie. 2007. An Array of Qualitative Data Analysis Tools: A Call for Data Analysis Triangulation. School Psychology Quarterly 22: 557-84. [CrossRef]

Long, Michael, and Peter Robinson. 1998. Focus on Form: Theory, Research and Practice. In Focus on Form in Classroom Second Language Acquisition. Edited by Catherine Doughty and Jessica Williams. Cambridge: Cambridge University Press, pp. 15-41.

Luke, Christopher L., and Jody S. Britten. 2007. The Expanding Role of Technology in Foreign Language Teacher Education Programs. CALICO Journal 24: 253-67. [CrossRef]

Mackey, Alison. 2006. Feedback, Noticing and Instructed Second Language Learning. Applied Linguistics 27: 405-30. [CrossRef]

Mackey, Alison, and Susan M. Gass. 2016. Second Language Research, 2nd ed. New York: Routledge.

McDermott, Geraldine. 2017. Towards a Culturally Responsive Pedagogy in Online Teaching: An Irish Perspective. AISHE-J: The All Ireland Journal of Teaching and Learning in Higher Education 9: 3111-19.

Mohan, Bernard A. 1986. Language and Content. Reading: Addison Wesley.

Moll, Luis C., Cathy Amanti, Deborah Neff, and Norma González. 1992. Funds of Knowledge for Teaching: Using a Qualitative Approach to Connect Homes and Classrooms. Theory into Practice 31: 132-41. [CrossRef]

Moore, Sarah Catherine K. 2009. Uses of Technology in the Instruction of Adult English Language Learners. CAELA NETWORK Brief. Available online: http:/ / www.cal.org/adultesl/pdfs/uses-of-technology-in-theinstruction-of-adult-ell.pdf (accessed on 1 December 2018).

Nero, Shondel, and Dohra Ahmad. 2014. Vernaculars in the Classroom: Paradoxes, Pedagogy, Possibilities, 1st ed. New York: Routledge.

Osborn, Terry A. 2006. Teaching World Languages for Social Justice: A Sourcebook of Principles and Practices, 1 st ed. Mahwah: Routledge. 
Pongsiriwet, Charuporn. 2001. Relationships among Grammatical Accuracy, Discourse Features, and the Quality of Second Language Writing: The Case of Thai EFL Learners. Morgantown: West Virginia University Libraries.

Rodriguez-Arroyo, Sandra, and Ashley Brailsford Vaughns. 2015. Is Service-Learning the Answer? Preparing Teacher Candidates to Work with ELLs through Service-Learning Experiences. New Waves-Educational Research and Development Journal: Special Issue on Service Learning in Education 18: 18-35.

Savin-Baden, Maggi, and Claire Howell Major. 2013. Qualitative Research: The Essential Guide to Theory and Practice. London: Routledge.

Schleppegrell, Mary, and Frances Christie. 2018. Linguistic Features of Writing Development: A Functional Perspective. In The Lifespan Development of Writing. Edited by Charles Bazerman, Arthur N. Applebee, Virginia W. Berninger, Deborah Brandt, Steve Graham, Jill V. Jeffery, Paul Kei Matsuda, Sandra Murphy, Deborah Wells Rowe, Mary Schleppegrell and et al. Urbana: NCTE (National Council of Teachers of English), pp. 111-50.

Tardy, Christine M. 2016. Beyond Convention: Genre Innovation in Academic Writing. Ann Arbor: University of Michigan Press.

TOOLS. n.d. Tools for CLIL Teachers. Available online: http://languages.dk/tools/index.htm (accessed on 12 December 2018).

Warschauer, Mark, Michele Knobel, and Leeann Stone. 2004. Technology and Equity in Schooling: Deconstructing the Digital Divide. Educational Policy 18: 562-88. [CrossRef]

(C) 2019 by the authors. Licensee MDPI, Basel, Switzerland. This article is an open access article distributed under the terms and conditions of the Creative Commons Attribution (CC BY) license (http://creativecommons.org/licenses/by/4.0/). 